\title{
AN ASSESSMENT OF BIODIVERSITY IN THE REKAWA, USSANGODA AND KALAMETTYA INLAND COASTAL ECOSYSTEMS IN SOUTHERN SRI LANKA
}

\author{
W P N Perera, M SJ Perera, R Rodrigo, N Peiris, \\ V A M P K Samarawickrema, S P Ekanayake and C N B Bambaradeniya \\ IUCN-The World Conservation Union, Sri Lanka
}

The survey was carried out to document the status of inland biodiversity in the Rekawa, Ussangoda and Kalametiya area along the Southern coastal zone of Sri Lanka. The survey extended from October 2002 - March 2003 (6 months). A reconnaissance survey of the inland areas was conducted, prior to the regular field sampling, in order to select representative sampling sites within the Ruk area. Eight sites were selected for regular field sampling at fortnightly intervals, and the plants and animals of the area were surveyed in a scientific manner, using appropriate sampling techniques.

The survey area harbours a variety of natural and man-made vegetation/habitat types, including both terrestrial and wetland systems. A total of 287 plant species belonging to 222 genera under 94 families were documented from the above inland vegetation/habitat types of the Ruk area. Several sub types of Mangroves, based mainly on floristics, could be found in the RUK area. These include the Lumnitzera dominated stands (Rekawa), Ceriops dominated stands (Rekawa), Avicennia dominated stands (Rekawa), Mixed stands (Rekawa, Kahanda), Excoecaria dominated stands (between Lunawa and Kalametiya) and Sonneratia dominated stands (Kalametiya, Malpeththawa). It is interesting to note that some mangrove stands are represented by only a single species.

A total of 328 species of vertebrates were recorded from the RUK area, of which 14 species $(4 \%)$ are endemic, while 27 species $(8 \%)$ are nationally threatened. The vertebrates include 52 species of fish, 17 species of amphibians, 49 species of reptiles, 184 species of birds, and 26 species of mammals. The invertebrates include 72 species of colorful butterflies, 25 species of terrestrial molluscs ani 9 species of aquatic mollusus. Three beach stretches that are important turtle nesting sites, eleven birding hotspots and three bird roosting sites were identified within the RUK area.

The study area has been identified for major development initiatives, under the Southern Development Programme of the Government of Sri Lanka. Therefore, the relevant conservation agencies should take steps to ensure that, biodiversity conservation concerns are adequately addressed in specific developmental activities planned for the area.

Proceedings of the Ninth Annual Forestry and Environment Symposium 2003 of the Department of Forestry and Environmental Science, University of Sri Jayewardenepura. Sri Lanka 